\title{
A Conceptual Social Media Tool for Supporting Collaborative University-Industry R\&D Programs
}

\author{
Gabriela Fernandes ${ }^{1}$, Clarisse Pessoa ${ }^{2}$, Ana R. Martins ${ }^{1}$, Eduardo B. Pinto ${ }^{1}$, Teresa Ruão ${ }^{2}$, Madalena Araújo ${ }^{1}$, \\ António J. Pontes ${ }^{1}$, Ricardo J. Machado ${ }^{1}$ \\ ${ }^{1}$ School of Engineering \\ University of Minho \\ Guimarães, Portugal \\ g.fernandes@dps.uminho.pt \\ ${ }^{2}$ Communication and Society Research Centre \\ University of Minho \\ Guimarães, Portugal \\ clarissepessoa@ics.uminho.pt
}

\begin{abstract}
This paper aims to help professionals and academics involved in collaborative university-industry $R \& D$ programs and projects, by presenting a conceptual social media tool that can be used to improve communication and collaboration between internal stakeholders. The social media tool conceptualization was developed based on a case study research strategy. The case selected was a large publicly funded $R \& D$ collaborative program that covers $30 R \& D$ projects carried out by a university and an industry partner. During the case study analysis three research methods were applied: participant observation, document analysis, and focus groups. The social media tool is conceptualized in seven functional building blocks: identity, relationships, sharing, presence conversations, reputation and groups. For each building block, its main objectives and requirements are detailed, within this particular context of collaborative university-industry $R \& D$ programs and projects.
\end{abstract}

Keywords - Program and project management; social media tools; communication; university-industry $R \& R$ collaboration

\section{INTRODUCTION}

Collaborative university-industry Research and Development (R\&D) projects are increasing and their importance to innovation and national economies growth is gaining more and more recognition [1]. In fact, there are several benefits resultant from these collaborations [2]. Literature research concerning university-industry collaboration has concentrated primarily on the existence and effects of the socalled cultural gap. However, the majority of the problems associated with the cultural gap can be alleviated by good project management (PM) [3].

PM has become an essential element of increased value to organizations in general $[4,5]$. Regardless of the industry, the organizations continuously strive to improve their systems and business processes, to preserve a competitive advantage [6]. The success in PM encompass not only the adoption of best practices but also its institutionalization, i.e. it is only the routine use of the PM practices and the strong contextualization (customization) and integration with other contextualized management practices in the organization, and the sense of 'ownership' facilitated by the staff involvement at all levels, that result in PM practices embeddedness in the organization [7].

Communication practices in PM context are essential for projects success, as it is recognized in the main PM bodies of knowledge [8-10]. There are different dimensions in PM where communication is used as a strategic tool, especially regarding its implications in human interaction, knowledge exchange, team work, and creativity enhancement or innovation development [11]. In fact, human action is always supported by communication and its process is permanently outlined by the social and cultural conditions of the organization where it occurs [12].

In projects, several stakeholders need information from different sources to perform their work, which implies the organization and sharing of project information. Projects with higher complexity also verify an increasing complexity in team communication [13].

The importance of the usage of social media tools in PM becomes evident with the increasing need to integrate project's stakeholders, to treat the information according different stakeholders' needs, and to intuitively share information among stakeholders and particularly among project teams [14]. Projects have social processes with some level of unpredictability, as there is a growing need for collaborative interaction between the various participants [15].

Social media tools have become an accessible alternative to traditional communication channels. These tools raised the volume and velocity of daily communication and information exchange. Social media tools provide the means to share, cooperate, co-create, ease information flows, debate and modify content, etc., providing a significant enhancement to communication [16].

Hereupon, organizations need ground-breaking approaches to address projects internal communication challenges. The usage of social media tools offers great opportunities to allow teams to collaborate and exchange information, enhancing project collaboration and coordination, to accomplish both project's and organization's targets [16].

In the context of collaborative university-industry $R \& D$ programs and projects, effective communication assumes particular importance to its success [17]. The research here reported examines the problem of improving communication and collaboration between internal stakeholders under collaborative university-industry $\mathrm{R} \& \mathrm{D}$ programs and projects through the usage of social media tools. 
A collaborative university-industry $R \& D$ program is a set of related projects, defined as a temporary organization that seek to accomplish specific objectives and mutual interests of the parties involved and have only the necessary duration to achieve these aims, thus ending when they are accomplished. These typology of programs or projects involves a collaborative work environment, within a specific context, with heterogeneous partners, collective responsibilities and, in most cases, with public funding support [18]. University-industry collaborations are based on interactive relationships of trust and commitment between partners aiming to create mutual value over time, which allows diffusion of creativity, ideas and skills, hence promoting a bilateral exchange of knowledge [19].

Based on a large collaborative university-industry R\&D program case study, covering 30 collaborative R\&D projects, this paper addresses the research question: What are the main characteristics of a social media tool to improve communication and collaboration between internal stakeholders in collaborative university-industry $\mathrm{R} \& \mathrm{D}$ programs? Therefore, the study is operationalized through the attainment of the following research objectives (Obj.):

- (Obj.1) Find out what communication tools internal stakeholders use to communicate in the collaborative university-industry $\mathrm{R} \& \mathrm{D}$ program.

- (Obj.2) Identify the main communication issues in the collaborative university-industry R\&D program.

- (Obj.3) Identify the main objectives and requirements of a social media tool to improve communication and collaboration between internal stakeholders in collaborative university-industry R\&D programs and projects.

Internal stakeholders are groups or individuals who work or are directly involved in the R\&D programs, e.g., the steering committee's members, program coordination's members (e.g., program director, program manager), Program and Project Management Office's members (e.g., Project Management Officers, Program and Project Management Communication member), project managers, project team members.

This paper follows a commonly used structure. The second section presents the literature review on some relevant communication concepts and the use of social media tools in PM. The third section provides the research methodology applied, including a description of the case study. The fourth section presents the case study communication audit, reporting on the main communication tools used (Obj.1) and main communication issues (Obj.2). The fifth section describes the social media tool main objectives and requirements proposal for improving communication and collaboration between internal stakeholders in collaborative university-industry R\&D programs and projects (Obj.3). Finally, the last section addresses the conclusions and final considerations about this study, as well as suggestions for future research work.

\section{LITERATURE REVIEW}

\section{A. Communication in Project Management}

According to Project Management Institute (PMI) [9], Project Communications Management comprises three processes: plan communications management, manage communications, and monitor communications. An inadequate communication's plan may lead to several complications, e.g. delays in message delivery, communication of information to the wrong audience or insufficient communication to the stakeholders, and misunderstanding the message [9]. Efficient communication engages everyone who interacts with the project and makes them understand their role within. Furthermore, good communication skills will simplify the understanding by other people that, for instance, are not familiarized with the work, and reduce the possibilities of being misunderstood [20].

The project manager plays an important role in the project communication, assuming the responsibility to lead the communication with all the project's stakeholders. The effective project communication conducted by a Project Manager impacts and influences all stakeholders positively, contributing to the whole project's effective management [21].

Establishing channels for communication and information exchange is crucial for the project's success [22]. Still, success is an ambiguous word, and its definition can vary from a project to another according to the context and stakeholders' interests $[23,24]$. In the context of collaborative $R \& D$ projects, Fernandes, Pinto, Araújo, Magalhães and Machado developed method specially devoted to quantitatively measure the success of collaborative university-industry $\mathrm{R} \& \mathrm{D}$ funded contracts, which could be managed as a singular project or a program of project [25].

Communication allows projects and the organization to work efficiently [9]. Thereby, communication is seen as a "function that integrates cost, scope and time to achieve a quality product and may be having a cornerstone function " [21, p. 1009], which means that it assists in achieving the cost, scope, time and quality goals of the project's objectives. Communication requires a reciprocal interaction between the team members and other project stakeholders, to transmit and share information and knowledge [20]

All projects share the need to communicate project information. Thus, discussing communication without mentioning information is impossible. It is mandatory to define the methods of storage, retrieval and distribution of the project's information, appropriately documented, during the project life cycle [9]. According to the PMI [9], it is imperative to consider the following aspects about project information: 1) who needs it and who is authorized to access it; 2) when it will be needed; 3 ) where and in which format it must be stored; 4) how to retrieve it; and 5) time zone, linguistic and cross-cultural considerations and barriers. However, projects differ from each other, which means that the information needs and distribution channels among project teams and stakeholders may vary widely [9].

In short, social media can improve substantially the project's communication and help achieving its success [22]. A project is an effort where people work together for a shared goal and purpose, and should also count on a social system of communication and collaboration in order to succeed [26]. Furthermore, communication and collaboration drive projects and share the need for correctly distribute information in a right way [27]. 


\section{B. Social Media Tools in Project Management}

Over time, PM developed its concepts and is taken as an approach to help organizations to efficiently operate. PM is no longer just a sub-discipline of engineering, it turned into an significant issue in many organizations for strategy implementation, business transformation and continuous improvement [15].

Today, project teams are pressured to increase their performance and must solve problems that occur during the project's lifecycle. Besides, projects are becoming more complex and dynamic [28]. In response, methods, technologies and techniques related to $\mathrm{PM}$, to collaboration and communication, have been developed to support teams with their work and support project managers supervising projects [26].

Social media tools and networks have been rising over the last few years. They have initially been created for friends to stay connected, but rapidly grown into a method for business to communicate internally and externally. As such, social media is changing how project team members communicate, affecting the processes involved with information services supporting PM [29]. Project managers have the opportunity to go further using conventional tools such as email, shared folders and repositories, and should learn and take advantage of social media within the PM practice [27].

Usually, coordination and communication in PM use a topdown approach. Traditional PM tools are complex and often lack real time communication and collaboration capabilities [27]. Furthermore, these traditional PM tools endorse a centralized type of control and a restricted access to information, which, once again, goes against the objective of ease of use and total sharing of information [28].

The instrumental lifecycle image of projects as a linear sequence of tasks to be performed on an objective entity 'out there', using codified knowledge, procedures and techniques, and based on an image of projects as temporary apolitical production processes, needs to change into concepts and images which focus on social interaction among people [15].

Social processes are a method of interaction established between individuals or teams [15]. Collaboration is one example of social processes. One of the advances in project knowledge management is the recognition of the significant part that "social processes, practices and patterns have in effectively managing project knowledge" [30, p. 474], because there is a need to develop knowledge based on the social processes and practices within the organization. Project managers want to improve relationships and hence, they need to increase the levels of trust and respect of the people working together and they must maximize the project's knowledge management. Moreover, the organization has to acknowledge the social network it is involved in and the selection of the collaborators by the project managers has to be in line with it [30].

Project managers have been using email as the preferential tool for communication, exchanging information such as reminders, assignments, meeting minutes, reports, etc. They also must ensure that the information reaches everyone from the bottom (project team) to the top (upper management).
Consequently, the traditional model of PM faces a challenge because of the increased volume of emails and the variety and speed of daily information which can become overwhelming and could compromise projects' outcomes $[22,27]$. Thus, it can be assumed that the traditional PM practices and techniques, such as centralized planning and control, are rendered ineffective for most of today's projects [31].

Some companies have started using social media tools to promote interaction between team members and customers. Because of their ease of use, social media are an efficient tool for communication and collaboration. Being these concepts crucial in projects, it is expected that social media can also offer opportunities for its application in project teams [32].

Using social media tools as a communication channel in projects is a non-traditional way of organizing projects and managing their performance and progress targeted at delivering, at enterprise level, a shared goal for the business, but harnessing the performance advantages of collaborative community [26].

Similarly, the usage of social media tools in PM is meant to facilitate the traditional PM process, enabling the team collaboration process and enhance communication among team members. The way in which social media tools are applied produces no change in the tasks to be performed, it changes the way tasks are executed and provides different outcomes of various tasks [33].

\section{1) Social Media Functionality}

Molendijk [34] argues that social media tools are very helpful, easy to use and have great influence in several aspects of teamwork, such as communication, coordination, mutual support, balance of member contribution, effort and cohesion. Social media has, thus, a diversity of functions, and each one adds value depending on the organization environment.

The honeycomb framework, proposed by Kietzmann, Hermkens and McCharthy [35], conceptualizes seven functional building blocks that help addressing the lack of understanding about what social media are and the forms they can take. Figure 1 presents the framework.

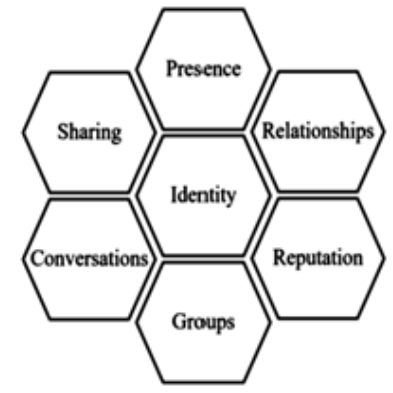

Fig. 1. Honeycomb framework, as proposed by Kietzmann, Hermkens and McCharthy [35].

The identity functional block represents the extent to which users reveal themselves. The conversations block represents the extent to which users communicate with other users. Sharing represents the extent to which users share, receive and distribute content. The block presence represents the extent to which users can know if other users are available and/or accessible. The 
presence is directly related with all the other functional blocks. The relationships block represents the extent to which users relate to other users. Reputation is the extent to which users can identify the social standing of others, including themselves. The groups functional block represents the extent to which users are ordered and can form communities [35].

\section{2) Social Media Tools for Project Management}

The use of social media tools brings several benefits to PM, not only for communication and collaboration, but also for supporting knowledge management, training, and innovation [36]. Social media tools are also useful when responding to project emergencies, as the delivery of information in real time through social media can help to better understand a project crisis and take adequate actions by the project team [37].

Chui, Manyika, Bughin, Dobbs, Roxburgh, Sarrazin, Sands and Westergren [36] present a list of major social media tools. The following paragraphs present a brief description and analysis of each one of them:

- Wiki: web application that allows content edition in a collaborative environment. These are particularly useful for projects and organizations within knowledge creation and information sharing. This tool can include different applications. Also, wikis are easy to search, since it is fast to access relevant information and update it.

- Discussion forum: functionality that allows discussing topics within communities.

- Shared workspace: virtual space that allows the access all information about the project, enabling its members to create content, manage tasks and analyze the progress.

- Social networks: provide collaboration inside the organization and improve trust in relationships between users.

- File and media sharing: the most important features are the possibility of accessing documents for co-creation of content and a fast access to the files by all project team members.

- Blog: allow to publish and discuss articles and experiences. Blogs are used to share information with a greater number of users. They are also a great way to keep the team informed about the work accomplished and of what is expected to come on the next project's phases. Should be updated in a weekly basis.

- Instant Messaging: enables a real time communication, allowing for quick answers to questions. Generally, this functionality is the fastest method to communicate between team members dispersed across different locations. Also, the possibility of storing conversations is available.

\section{3) Social Media Benefits and Barriers}

The web-based collaboration tools are usually easier to organize and to use, and provide greater user experience in comparison to classical tools [27]. Social media allows to create a "distributed collaboration environment where the team can share ideas, collaborate, communicate, and pool resources regardless of geographical constraints" [27, p. 4]. According to a McKinsey study [38], the top benefits for companies using social media tools internally are: increased speed of access to knowledge; reduced communication costs; increased speed of access to internal experts; and reduced travel costs.

Based on the theoretical research developed by Sponselee [39], it is possible to list several positive effects of social media tools on PM:

- Enable real time project information: it is important for team members and stakeholders to have updates on the project status, short discussions or share new documents' versions or other content. Furthermore, a timely information delivery is crucial for making the right decisions regarding project progress.

- Support iterative and incremental PM: users can effortlessly chat with each other to quickly make decisions on how to proceed in response to changes to the plan.

- Improve project efficiency: social media eases the creation of communities and groups where team members can discuss and build information, share documents, create profiles, analyze risks and plan. It works as a centralized place where the latest information is saved, project documents are built, and content related discussions start, allowing team members to react fast and effortlessly.

- Simplify remote working: independently of time and location, social media provides the access to information, offering employees the possibility of working even if they are not at the office.

- Facilitate project branding: project and organization pages on social media are very common; they "can increase the project visibility and also contribute to a positive project reputation" [39, p. 30]. These are used to inform project team members and stakeholders on subjects such as the project scope and goals, project status, project risks, delivered results, and other relevant information.

- Stimulate related discussions: social media encourages the sharing of knowledge and experiences among users and facilitate discussions. A positive effect is that the team members may use the all members' knowledge, instead of just one's own (which is limited).

All these positive effects show that the adoption of social media tools for project communication is seen as useful for team members and for the overall stakeholders. All these effects increase the value of the collaboration between project team members and make it easier to involve and inform project stakeholders. As a matter of fact, social media tools influence on team empowerment. However, the adoption of social media tools may also experience a few barriers. According to studies carried out by Sponselee [39] and Harrin [40], relevant barriers to social media adoption are now briefly presented:

- Overwhelming number of social media tools: the number of social media tools has been growing and it is not possible, neither needed to use all of them. If too many social media tools are adopted, constantly updating them will become time-consuming, and the efficiency gains will be lost. 
- Concerns about data security: using social media can be a problem since "much valuable information is shared in open space where it may get in the hands of people that should not know about it"' [39, p. 31]. Organizations are also concerned about where the data is stored, and how can it be backed-up and recovered. Also, organizations are also worried about system abuse.

- Negative publicity: it is very simple to an individual to "reach many people with an opinion or statement"' $39, \mathrm{p}$. 31 , thus a negative comment can be seen by a lot of people and produce serious negative effects on the project.

- Lack of proven business value: there is a lack of information and a nonexistence of case studies on the importance of adopting social media tools on business.

- Concerns about information overload: some specialists argue that social media tools will create a large quantity of unmanageable data, resulting in concerns over control of data flows and worries about being overwhelmed with insignificant communications.

- Fading line between work and private spheres: project team members are afraid that, using social media tools, project managers will monitor their work (inside and outside working hours). Although there are clear advantages of having personal data reachable from anywhere, collaborators must deal with the drawback of the blurring of lines between the personal and professional spheres.

Although there are still some concerns about the use of social media tools for project communication, there are several benefits of using a social media tools within projects.

\section{RESEARCH METHODOLOGY}

An exploratory research was carried out, aiming to learn from the experience of program and project internal stakeholders of one case study, namely to understand what the main communication issues are, in the particular context of collaborative university-industry $\mathrm{R} \& \mathrm{D}$, and what the key stakeholders' perceptions are of what are the main objectives and requirements of a social media tool to support the communication and collaboration of such initiative. Case study is perceived by researchers as one of the most used research strategies [41]. By using them, researchers can focus on a particular phenomenon and discover crucial knowledge [42].

\section{A. Case Study Background}

This study was conducted in a funded R\&D collaborative program that covers $30 \mathrm{R} \& \mathrm{D}$ projects, and that has joined a company and a university in a research and technological development initiative targeting critical $\mathrm{R} \& \mathrm{D}$, regarding the development and production cycle of innovative and advanced multimedia systems for the automobile industry. The case selected amount to a total investment of above $55 \mathrm{M} €$, over the period of 36 months, between 2015 and 2018. The program and all its constituent projects have an expected is expected to work for 36 months and has more than 500 individual participants from university and industry, of which about 200 are working full time exclusively on the $R \& D$ projects that compose the program.
Since program initiation phase, the Program Coordination understood communication as a key area. Therefore, it was created a specific role in the Program and Project Management Office (PgPMO): PgPMO Communication [43]. However, a recent survey, directed to program internal stakeholders, shown that the questionnaire items which presented lower degree of satisfaction were the practices and mechanisms adopted for internal communication (3.5) and the alignment between the industry and university teams in the execution of the project in which they were involved in the program (3.4). The scale used to evaluate the satisfaction was the 5-point Likert scale, where " 5 " indicates "very high" and " 1 " indicates "very low". These results are based on 187 completed questionnaires, received from a total of 473 invitations sent by email (rate response of $40 \%$ ). The results show the importance on to improve communication tools, namely by a social media tool.

\section{B. Research Methods}

This study followed a multi-method research since the data were collected through three different methods: participant observation, communication audit and focus group.

Participant observation requires the researcher to assume different roles and use several techniques to collect data, without forgetting her/his primary role [44]. The observer enters the community of those to be observed and tries to participate in their activities by becoming a member of their workgroup, organization or community [42]. Different program internal stakeholders were observed in naturally occurring situations, namely during regular management and technical meetings.

It was conducted a communication audit to evaluate the communication system, through a complete analysis of its tools, their potential and effective uses, benefits and issues associated with the usage of these tools, and the communication direction. Hence, it allowed the development of a communicative perspective of the program stakeholders.

The focus groups consisted in gathering a group of experts to collectively explore the social media tool objectives and requirements and collect their opinions on the usage of social media tools to support internal stakeholders' communication and collaboration [45]. The preparation and the conduction of focus groups are, in many aspects, similar to interviews, as they involve formulating questions in advance and providing feedback on what one hears [46]. Focus groups' advantage over interviews and surveys is the ease of discussion and participation, enriching the information collected [47]. The focus groups had the participation of eight experts - the Program Manager, a Project Manager, a Project Team Member, four Program and Project Management Officers, and one Program and Project Management Communication member.

\section{CASE STUdy: COMmUnicAtion AUdit}

\section{A. Used Communication Tools}

Based on the participant observation and the communication audit, it was possible to attain the first research objective. Table I summarizes the results obtained. The communication tools used by the program's internal stakeholders are a document management system (DMS) from the company, but make available for all internal stakeholders, including university 
stakeholders, as the formal shared workspace to access all information about the program and projects, Outlook, Skype and the mobile phone. For each tool, it was analysed their communication's direction, potential and effective uses, and theirs benefits and issues associated with their usage.

TABLE I. USED COMUNICATION TOOLS ANALYSIS

\begin{tabular}{|c|c|c|c|c|}
\hline & DMS & Outlook & Skype & Mobile phone \\
\hline ن气 & $\begin{array}{l}1 . \\
\text { Multidirection } \\
\text { al } \\
\text { communicatio } \\
\text { n (one to } \\
\text { many). }\end{array}$ & $\begin{array}{l}\text { 1. Mostly } \\
\text { bidirectional, } \\
\text { using the } \\
\text { question- } \\
\text { answer model, } \\
2 . \\
\text { Occasionally } \\
\text { there is } \\
\text { multidirection } \\
\text { al } \\
\text { communicatio } \\
\text { n. }\end{array}$ & $\begin{array}{l}\text { 1. Mostly } \\
\text { bidirectional, } \\
\text { using the } \\
\text { question- } \\
\text { answer model, } \\
2 . \\
\text { Occasionally } \\
\text { there is } \\
\text { multidirection } \\
\text { al } \\
\text { communicatio } \\
\text { n. }\end{array}$ & $\begin{array}{l}\text { 1. Mostly } \\
\text { bidirectional } \\
\text { (one to one), } \\
\text { using the } \\
\text { question- } \\
\text { answer model. }\end{array}$ \\
\hline 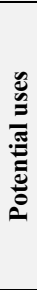 & $\begin{array}{l}\text { 1. Manage } \\
\text { documents; } 2 . \\
\text { Store } \\
\text { documents; } 3 \text {. } \\
\text { Tracking } \\
\text { documents; } 4 \text {. } \\
\text { Documents } \\
\text { synchronizatio } \\
\text { n; } 5 \text {. Share } \\
\text { documents. }\end{array}$ & $\begin{array}{l}\text { 1. Meetings } \\
\text { appointment; } \\
\text { 2. Calendar } \\
\text { sharing; } 3 \text {. } \\
\text { Sending e- } \\
\text { mail; } 4 \text {. } \\
\text { Checking } \\
\text { profiles. }\end{array}$ & $\begin{array}{l}\text { 1. Video calls; } \\
\text { 2. Voice calls; } \\
\text { 3. Quick } \\
\text { chatting. }\end{array}$ & $\begin{array}{l}\text { 1. SMS; } 2 . \\
\text { Phone calls; } 3 . \\
\text { Video calls. }\end{array}$ \\
\hline 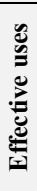 & $\begin{array}{l}\text { 1. Share } \\
\text { documents; } 2 . \\
\text { Documents } \\
\text { synchronizatio } \\
\text { n; } 3 \text {. Store } \\
\text { documents. }\end{array}$ & $\begin{array}{l}\text { 1. Sending e- } \\
\text { mail; } 2 \text {. } \\
\text { Scheduling } \\
\text { meetings. }\end{array}$ & $\begin{array}{l}\text { 1. Video calls; } \\
\text { 2. Voice calls. }\end{array}$ & 1. Phone calls. \\
\hline ڤึ: & $\begin{array}{l}\text { 1. Storage } \\
\text { location; } 2 \text {. } \\
\text { Security and } \\
\text { access control; } \\
\text { 3. Private. }\end{array}$ & $\begin{array}{l}\text { 1. Free } \\
\text { platform; } 2 \text {. } \\
\text { Available for } \\
\text { multiple } \\
\text { platforms; } 3 \text {. } \\
\text { Formal } \\
\text { communicatio } \\
\text { n channel; } 4 \text {. } \\
\text { The most } \\
\text { popular } \\
\text { communicatio } \\
\text { n tool. }\end{array}$ & $\begin{array}{l}\text { 1. Free } \\
\text { platform; } 2 . \\
\text { Available for } \\
\text { multiple } \\
\text { platforms. }\end{array}$ & $\begin{array}{l}\text { 1. Provides } \\
\text { offline } \\
\text { communicatio } \\
\mathrm{n} ; 2 \text {. Provides } \\
\text { a fast and } \\
\text { informal way } \\
\text { to } \\
\text { communicate. }\end{array}$ \\
\hline$\stackrel{\ddot{g}}{\Xi}$ & $\begin{array}{l}\text { 1. Users are } \\
\text { not notified } \\
\text { when a } \\
\text { document is } \\
\text { added/updated } \\
; 2 \text {. Only final } \\
\text { versions are } \\
\text { stored. }\end{array}$ & $\begin{array}{l}\text { 1. Delays in } \\
\text { responses, } \\
\text { which leads to } \\
\text { more delays. }\end{array}$ & $\begin{array}{l}\text { 1. Not adopted } \\
\text { by all internal } \\
\text { stakeholders; } \\
\text { 2. Low } \\
\text { frequency of } \\
\text { use by internal } \\
\text { program } \\
\text { stakeholders }\end{array}$ & $\begin{array}{l}\text { 1. Privacy } \\
\text { issues; } 2 \text {. Use } \\
\text { of the personal } \\
\text { device to } \\
\text { communicate } \\
\text { at professional } \\
\text { level. }\end{array}$ \\
\hline
\end{tabular}

The most popular communication tool among internal program stakeholders is Outlook. Outlook is a free email client, develop by Microsoft, which also offers other functionalities (e.g. calendar sharing and meetings scheduling). Although, it is mainly used for exchanging emails, using the question-answer model. It is a very convenient option for formal communication, but delayed responses can generate even more delays (e.g. in decision making, change approval, and meetings scheduling).

Skype is another communication tool developed by Microsoft. It provides free video and phone calls, as well as quick chatting, relevant features for informal communication But, on the other hand, several team members do not use it.

The personal mobile phone is also used among internal program stakeholders, as it provides a fast way to obtain fast answers to simple questions. Although, this tool has privacy issues and members can decide to share or not share their personal contact with other internal program stakeholders. Using the personal mobile phone also fades the line between work and private spheres.

\section{B. Communication Issues (CI)}

Data obtained from participant observation, communication audit and focus group were analyzed, resulting in the following list of main problems and difficulties of communication among internal program stakeholders (Obj.2):

CI.1 Communication politics not embed: although there is a formal definition of who communicates what, in the various subjects related to the projects, within project teams and by program coordination, in practice this is not accomplished.

CI.2 Unstructured communication channels: there are no rules on which channels to use for the various communication situations: formal and non-formal. For example, email is the communication channel most used by project teams, but for more trivial matters, it generates unnecessary bureaucracy.

CI.3 Lack of recognition of the existing communication structure by the internal stakeholders: several stakeholders do not recognize that there is a communication structure to follow, this cause some problems in the communication process among them.

CI.4 Lack of trust between internal stakeholders: this sometimes lead to a limited amount and quality of shared information, creating communication difficulties (e.g., if stakeholders are not all aware of all the existing information, how can they express their opinion on a subject in a sustained way?)

CI.5 Geographical barriers: project team members are distributed over different geographic locations. This factor brings some issues, namely related with travelling and bringing up the need for information accessibility anywhere and anytime.

CI.6 Concerns about information sharing: not everyone has access to the information needed to perform their work, and some internal stakeholders do not understand the information flow (e.g., the internal stakeholders do not necessarily use the same information tools during a project).

CI.7 Standardized document storage is not embedded: collaborators of the same team, or working in the same project, store documents in different locations, with no standardization, creating difficulties in finding documents and information.

CI.8 Standardized workflow is not embedded: the processes are not embedded, creating difficulties in understanding inputs, outputs and in which direction the work should flow.

CI.9 Increasing number of collaborators: new collaborators find very difficult to understanding the processes in the organization. There is no available time to train new collaborators and there is some lack of documented and structured processes/activities. 
Therefore, the new collaborators cannot learn by resorting to explanatory documents.

CI.10 Language barriers: there are two formal languages used by internal program and projects stakeholders, Portuguese, the native language for most stakeholders, and English. However, there are some stakeholders with a lower level of language shills, which causes sometimes communication problems and difficulties.

CI.11 Vertical communication flaws: most of the communication weaknesses were found in vertical communication. The horizontal communication in most of the R\&D projects of the program run well.

\section{Social Media Tool for Supporting Collaborative UNIVERSITY- INDUSTRY R\&D PROGRAMS}

In order to help overcome the main communication issues presented above, it is proposed a conceptual social media tool, specifying its main objectives and requirements, which would allow to improve communication and collaboration between program and projects' internal stakeholders (Obj.3), resultant from participant observation and later explored by a focus group.

The main theoretical background used to its development was the honeycomb framework, proposed by Kietzmann, Hermkens and McCharthy [35], which identifies seven functional building blocks of a social media tool, discussed in literature review section. Sponselee's work is also taken into account, as the author tried to identify the different usage areas for each block of the honeycomb [39].

Figure 2 summarizes the social media social main objectives and requirements answering the third and last research objective. The creation of a social media tool, to be used by the particular context of collaborative university-industry R\&D programs and projects, as proposed in Figure 2, offers many advantages, e.g. provides communication structure (helping to solve CI.2), brings internal stakeholders together in the virtual world, breaking geographical barriers (CI.5) and allows informal communication and the recognition of the existing communication structure (helping to solve CI.3).

Some of the main objectives of creating a social media tool are intrinsically linked to the very objectives of a broader strategic communication plan. From a communicational point a view, it is very important that, in this kind of university-industry partnerships which are characterized as temporary organizations, features that promote commitment between stakeholders be developed, like, for example, the creation of symbolic value of the team member towards her/his role within the organization, the creation of a partnership's solid culture and, also, an awareness of the organization's dimension, so that internal stakeholders, in turn, may be aware of the impact of her/his work on program and project results. It is also important to build trust between different stakeholders, and the creation of a closer and more informal relationship between the various actors (creating groups/ communities) it helps in trust development which is enhanced through learning the other's history and promoting informal communication (helping to solve CI.4).

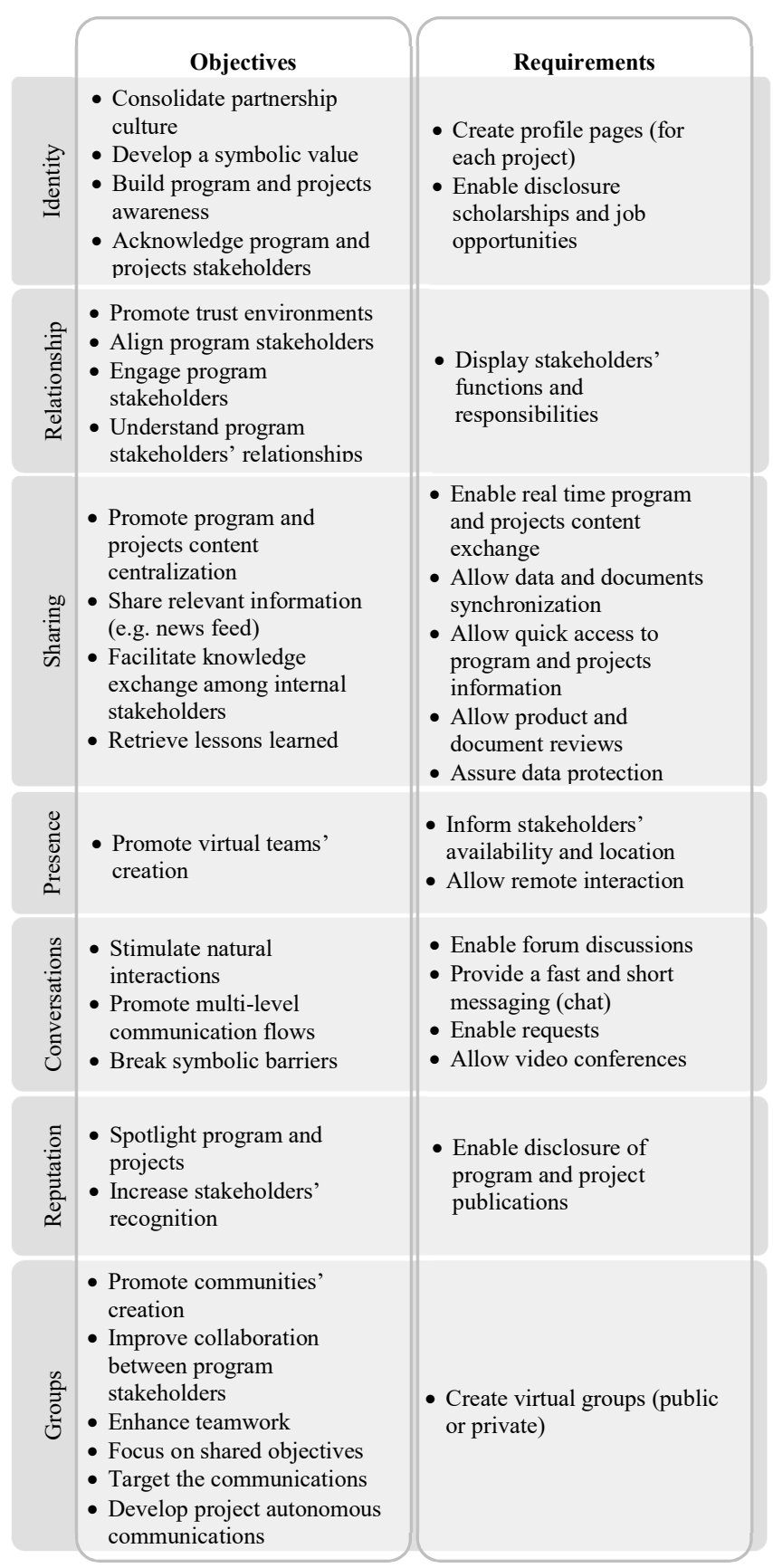

Fig.2. Social media tool objectives and requirements for supporting collaborative university-industry $R \& D$ programs

Considering that the context of this study is on partnerships between different institutions, it seems relevant to think about how to deal with the potential problems related not only to geographic barriers (CI.5) but also to symbolic distance (e.g., communication problems that stem from the constitution of a rigid hierarchy). Therefore, it is suggested the creation of groups in the social media tool that identify several projects within the program, which aimed the creation of their own culture and identity, improving communication and collaboration between 
the different internal stakeholders involved, encouraging team work and developing autonomous communication between teams (CI.4).

Besides, the conception of a social media tool can help the process of build communications politics (CI.1 and CI.6) because this platform allows the creation of many communications channels within the tool, to address different objectives.

In addition to the more general requirements to be included in the social media model proposal, it is point out a few more specific ones, such as the need that the social media tool can identify stakeholders' functions and responsibilities, through the creation of profile pages (helping to resolve the CI.5), and the possibility of, among other features, promoting virtual contact through video chats (CI.5), the possibility to make fast and short messaging, through a chat platform, or to make allow video conferences, that would promote multi-level communication flows and the break of symbolic barriers (helping to solve CI.10 and CI.11).

Communication issues like CI.7, CI.8 and CI.9 are more difficult to solve with a social media tool because depends on external factors (not only the communication ones).

In theory, the proposed social media tool covers all points about the usage of social media tools in programs and projects for internal communication and collaboration. Nonetheless, the proposed tool should not be used as an email replacement, as there is not an evidence on the quantitative impact of the move from email to a social media tool [48]. Also, email is a convenient tool for formal communication.

\section{CONCLUSIONS}

The main theoretical contribution of this research is the proposed conceptual social media tool, which was developed taken into account the particular the context of collaborative university-industry $R \& D$ programs and projects.

There is an unquestionable need for communication and collaboration between the program and projects internal stakeholders in this context. Social media tools improve the visibility of project's processes to everyone, increasing transparency and promoting a faster, smarter, and more efficient communication. Social media tools enhance how program and project stakeholders use related knowledge and refine each other's skills, while preserving the collective project knowledge base and improving stakeholders' communication and collaboration.

The literature review was crucial to better understand the use of social media tools in PM contexts, though this is a recent topic and therefore the literature is scarce and limited. The honeycomb framework, proposed by Kietzmann, Hermkens and McCharthy [35], was used as the main theoretical framework for the proposed conceptual social media tool, which comprises seven functional building blocks: identity, relationships, sharing, presence, conversations, reputation and groups.

To better understand the context and problem and define an appropriate solution, a case study was analysed using three research methods: participant observation, communication audit, and focus group. Firstly, it was identified the communication tools used by the program's internal stakeholders (Obj.1): DMS, Outlook, Skype and the mobile phone. The most used tool was the Outlook. Moreover, it were identified eleven communication issues (Obj.2): communication politics are not embed; unstructured communication channels; lack of recognition of the existing communication structure by the internal stakeholders; lack of trust between internal stakeholders; geographical barriers; concerns about information sharing; standardized document storage is not embedded; standardized workflow is not embedded; increasing number of collaborators; language barriers; and vertical communication flaws.

For each of the seven functional blocks are presented the main objectives and requirements of the social media tool (Obj.3, see Fig. 2). For example, for the functional block conversations the requirements are: enable short discussions, provide a chat platform, enable requests, and allow video conferences. The implementation of these requirements in a social media tool would stimulate natural interactions and promote multi-level communication flows between internal stakeholders and break symbolic barriers. A social media helps to solve part of the communication issues. However, it should not be thought as a substitute of face-to-face interactions, but a way to improve communication and collaboration.

Future research work is needed to model all the requirements identified for each functional block of the social media tool, to develop an IT software application in the future.

\section{ACKNOWLEDGMENT}

This research is sponsored by the Fundação para a Ciência e a Tecnologia FCT (SFRH/BPD/111033/2015), and by the Portugal Incentive System for Research and Technological Development. Project in co-promotion n ${ }^{\circ}$ 36265/2013 (Project HMIExcel - 2013-2015).

\section{REFERENCES}

[1] M. Perkmann, A. Neely, and K. Walsh, "How should firms evaluate success in university-industry alliances? A performance measurement system,” R\&D Manag., 41(2), 202-216, 2011.

[2] G. Fernandes, E. B. Pinto, M. Araújo, and R. J. Machado, "Planning Benefits Realization in a Collaborative University-Industry R\&D Funded Program,” 23rd ICE/IEEE Int. Technol. Manag. Conf., June, 1076-1084, 2017.

[3] T. A. Barnes, I. R. Pashby, and A. M. Gibbons, "Managing collaborative R\&D projects development of a practical management tool," Int. J. Proj. Manag., 24(5), 395-404, 2006.

[4] P. Eskerod and E. Riis, "Project management models as value creators," Proj. Manag. J., 40(1), 4-18, 2009.

[5] J. Thomas and M. Mullaly, "Understanding the value of project management: First steps on an international investigation in search of value," Proj. Manag. J., 38(3), 74-89, 2007.

[6] R. Jamaluddin, C. M. M. Chin, and C. W. Lee, "Understanding the requirements for project management maturity models: Awareness of the ICT industry in Malaysia," in IEEM2010 - IEEE International Conference on Industrial Engineering and Engineering Management, 2010, 15731577.

[7] G. Fernandes, S. Ward, and M. Araújo, "Improving and embedding project management practice in organisations - A qualitative study," Int. J. Proj. Manag., 33(5), 1052-1067, 2015.

[8] S. Ohara, P2M - A Guidebook of Project \& Program Management for Enterprise Innovation, Summary translation. Tokyo, 2005. 
[9] Project Management Institute, Project Management Body of Knowledge: A Guide to the Project Management Body of Knowledge, 6th ed. Project Management Institute, 2017.

[10] APM, Association for Project Management Body of Knowledge, 6th ed. Association for Project Management, 2012.

[11] T. Grundy, "Strategic project management and strategic behaviour," Int. J. Proj. Manag., 18(2), 93-103, 2000.

[12] E. A. Smith, "Communication and collective action: Language and the evolution of human cooperation," Evolution and Human Behavior, 31(4), 231-245, 2010.

[13] R. R. Senescu, G. Aranda-Mena, and J. R. Haymaker, "Relationships between Project Complexity and Communication," J. Manag. Eng., 29(2), 183-197, 2013.

[14] L. Van der Merwe, "Social Media Use within Project Teams: Practical Application of Social Media on Projects," in Strategic Integration of Social Media into Project Management Practice, G. Silvius, Ed. IGI Global, 2016, 139-159.

[15] M. Winter, C. Smith, T. Cooke-Davies, and S. Cicmil, "The importance of 'process' in Rethinking Project Management: The story of a UK Government-funded research network," Int. J. Proj. Manag., 24(8), 650$662,2006$.

[16] G. Silvius, "Social Project Management?," in Strategic Integration of Social Media into Project Management Practice, G. Silvius, Ed. IGI Global, 2016, 293-297.

[17] T. Barnes, I. Pashby, and A. Gibbons, "Effective university - Industry interaction: A multi-case evaluation of collaborative R\&D projects," Eur. Manag. J., 20(3), 272-285, 2002.

[18] J. vom Brocke and S. Lippe, "Managing collaborative research projects: A synthesis of project management literature and directives for future research,” Int. J. Proj. Manag., 33(5), 1022-1039, 2015.

[19] C. Plewa and P. Quester, "Key drivers of university-industry relationships: the role of organisational compatibility and personal experience," J. Serv. Mark., 21(5), 370-382, 2007.

[20] Ahdia Nazari, "Developing a Social Media communication Plan," in Strategic Integration of Social Media into Project Management Practice, G. Silvius, Ed. IGI Global, 2016, 194-217.

[21] B. Zulch, "Communication: The Foundation of Project Management," Procedia Technol., 16, 1000-1009, 2014.

[22] E. van Dokkum and P. Ravesteijn, "Managing Project Communication: Using Social Media for Communication in Projects," in Strategic Integration of Social Media into Project Management Practice, G. Silvius, Ed. IGI Global, 2016, 35-50.

[23] F. T. Berssaneti and M. M. Carvalho, "Identification of variables that impact project success in Brazilian companies," Int. J. Proj. Manag., 33(3), 638-649, 2015.

[24] D. Milosevic and P. Patanakul, "Standardized project management may increase development projects success," Int. J. Proj. Manag., 23(3), 181$192,2005$.

[25] G. Fernandes, E. B. Pinto, M. Araújo, P. Magalhães, and R. J. Machado, "A Method for Measuring the Success of Collaborative UniversityIndustry R\&D Funded Contracts," Procedia Comput. Sci., 121, 451-460, 2017.

[26] P. Taylor, The Social Project Manager - Balancing Collaboration with Centralised Control in a Project Driven World. Gower Publishing Company, 2015.

[27] Hamid Nach, "Project Management 2.0: Towards the Renewal of the Discipline," in Strategic Integration of Social Media into Project Management Practice, no. January, G. Silvius, Ed. Hershey PA, 2016, 115.
[28] H. Kerzner, Project management: a systems approach to planning, scheduling, and controlling. 2009.

[29] H. Remidez and N. B. Jones, "Developing a model for social media in project management communications," Int. J. Bus. Soc. Sci., 3(3), 33-36, 2012.

[30] N. J. Brookes, S. C. Morton, A. R. J. Dainty, and N. D. Burns, "Social processes, patterns and practices and project knowledge management: A theoretical framework and an empirical investigation," Int. J. Proj. Manag., 24(6), 474-482, 2006.

[31] R. E. Levitt, "Towards project management 2.0," Eng. Proj. Organ. J., 1(3), 197-210, 2011

[32] G. Silvius, Strategic Integration of Social Media into Project Management Practice. IGI Global, 2016.

[33] A. Manzoor, "Social Media for Project Management," in Strategic Integration of Social Media into Project Management Practice, G. Silvius, Ed. IGI Global, 2016, 51-65.

[34] Frank Molendijk, "The Influence of Social Media on Teamwork Aspects: Introduction of a Conceptual Model to Measure the Influence Social Media has on Teamwork," in Strategic Integration of Social Media into Project Management Practice, G. Silvius, Ed. IGI Global, 2016, 67-82.

[35] J. H. Kietzmann, K. Hermkens, I. P. McCarthy, and B. S. Silvestre, "Social media? Get serious! Understanding the functional building blocks of social media," Bus. Horiz., 54(3), 241-251, 2011.

[36] M. Chui, J . Manyika, J. Bughin, R. Dobbs, C. Roxburgh, H. Sarrazin, G. Sands, and M. Westergren, "The social economy: Unlocking value and productivity through social technologies," 2012.

[37] K. Boersma, D. Diks, J. Ferguson, and J. Wolbers, "From Reactive to Proactive Use of Social Media in Emergency Response," in Strategic Integration of Social Media into Project Management Practice, no. January, G. Silvius, Ed. 2016, 236-252.

[38] J. Bughin and M. Chui, "The rise of the networked enterprise: Web 2.0 finds its payday," 2010. [Online]. Available: https://www.mckinsey.com/industries/high-tech/our-insights/the-rise-ofthe-networked-enterprise-web-20-finds-its-payday.

[39] M. Sponselee, "Effects of Social Media on Project Management," in Strategic Integration of Social Media into Project Management Practice, G. Silvius, Ed. IGI Global, 2016, 16-34.

[40] E. Harrin, "Barriers to Social Media Adoption on Projects," in Strategic Integration of Social Media into Project Management Practice, G. Silvius, Ed. IGI Global, 2016, 106-124.

[41] R. K. Yin, Case Study Research: Design and Methods, 26, 5th. 2014.

[42] M. Saunders, A. Thornhill, and P. Lewis, Research Methods for Business Students, 7th ed. Edinburgh: Pearson Edication Limited, 2016.

[43] G. Fernandes, E. B. Pinto, M. Araújo, and R. J. Machado, "The Roles of a Programme and Project Management Office to Support Collaborative University-Industry R\&D,” Intern. Rep. Univ. Minho, 0(0), 1-26, 2017.

[44] L. Baker, "Observation: A Complex Research Method," Libr. Trends, 55(1), 171-189, 2006.

[45] R. A. Krueger and M. A. Casey, Focus groups: A practical guide for applied research. SAGE Publication, 2015.

[46] J. Langford and D. McDonagh, Focus Groups: Supporting Effective Product Development. London, 2003.

[47] J. Fernandes and R. J. Machado, Lecture Notes in Management and Industrial Engineering: Requirements in Engineering Projects. Springer, 2015.

[48] P. Wijngaard, A. Basten, I. Wensveen, and T. de Vries, "Projects without Email, Is that Possible?," in Strategic Integration of Social Media into Project Management Practice, G. Silvius, Ed. IGI Global, 2016, 218-235. 